\title{
Asthma prescribing, ethnicity and risk of hospital admission: an analysis of 35,864 linked primary and secondary care records in East London
}

\author{
Sally A Hull ${ }^{1,4}$, Shauna McKibben ${ }^{2,4}$, Kate Homer ${ }^{1}$, Stephanie JC Taylor ${ }^{2}$, Katy Pike ${ }^{3}$ and Chris Griffiths ${ }^{2}$
}

Inappropriate prescribing in primary care was implicated in nearly half of asthma deaths reviewed in the UK's recent National Review of Asthma Deaths. Using anonymised EMIS-Web data for 139 ethnically diverse general practices (total population 942,511) extracted from the North and East London Commissioning Support Unit, which holds hospital Secondary Uses Services (SUS)-linked data, we examined the prevalence of over-prescribing of short-acting $\beta_{2}$-agonist inhalers (SABA), under-prescribing of inhaled corticosteroid (ICS) inhalers and solo prescribing of long-acting $\beta_{2}$-agonists (LABA) to assess the risk of hospitalisation for people with asthma for 1 year ending August 2015. In a total asthma population of 35,864, multivariate analyses in adults showed that the risk of admission increased with greater prescription of SABA inhalers above a baseline of 1-3 (4-12 SABA: odds ratio (OR) 1.71; 95\% confidence interval (CI) 1.20-2.46, $\geqslant 13$ SABA: OR 3.22; 95\% Cl 2.04-5.07) with increasing British Thoracic Society step (Step 3: OR 2.90; $95 \% \mathrm{Cl} 1.79-4.69$, Step 4/5: OR 9.42; 95\% Cl 5.27-16.84), and among Black (OR 2.30; 95\% Cl 1.64-3.23) and south Asian adult populations (OR 1.83; 95\% Cl 1.36-2.47). Results in children were similar, but risk of hospitalisation was not related to ethnic group. There is a progressive risk of hospital admission associated with the prescription of more than three SABA inhalers a year. Adults (but not children) from Black and South Asian groups are at an increased risk of admission. Further work is needed to target care for these at-risk groups.

npj Primary Care Respiratory Medicine (2016) 26, 16049; doi:10.1038/npjpcrm.2016.49; published online 18 August 2016

\section{INTRODUCTION}

Frequent use of short-acting $\beta_{2}$-agonist (SABA) inhaler medication is a key indicator of poor asthma control, ${ }^{1,2}$ a risk factor for asthma exacerbations ${ }^{3}$ and a potentially modifiable risk factor for asthma-related death. ${ }^{4,5}$ Clinical guidelines recommend that those using more than one SABA canister (200 actuations) per month should have an early clinical review. ${ }^{5,6}$ The UK National Review of Asthma Deaths (NRAD) ${ }^{4}$ identified poor prescribing practice and a failure by clinicians to adhere to British Thoracic Society (BTS)/SIGN asthma guidelines. In 39\% of the 195 asthma deaths reviewed, $>12$ SABA inhalers had been prescribed in the previous year; $>50$ SABA inhalers had been prescribed in $4 \%$ of cases; and in $3 \%$ of cases long-acting $\beta_{2}$-agonist (LABA) monotherapy was prescribed without inhaled corticosteroid (ICS) preventer treatment. ${ }^{4}$

Asthma morbidity disproportionately affects people from ethnic minority backgrounds. ${ }^{7}$ Often concentrated in inner-city areas, $^{8,9}$ ethnic minorities often have poorer continuity with healthcare providers, ${ }^{10}$ less familiarity with primary healthcare practitioners ${ }^{11}$ and are more likely to present to Accident and Emergency Departments (AED) as a primary source of care. ${ }^{12}$ In 1998, UK hospitalisation rates for asthma in adults and children of black and south Asian origin were found to be higher than in the white British population. ${ }^{13}$ Recent data from Scotland showed an increased risk of hospitalisation for Pakistani and Indian adults ${ }^{14}$ but did not provide analyses for ethnic minority children. Figures for UK emergency asthma admission rates showed that the East London boroughs included in our study all had crude admission rates above the average for London (1.02/1000 population) in $2012-13 .^{15}$

Studies suggest that differences in asthma medication use may contribute to asthma morbidity in ethnic minority populations, ${ }^{16,17}$ yet these groups are often under-represented in asthma research.

Inappropriate use of asthma medications has been reported as a major contributor to uncontrolled asthma in inner-city populations, ${ }^{18,19}$ particularly in children from inner-city areas who are more likely to overuse SABA on a daily basis ${ }^{18}$ and are the least likely to receive adequate guideline-based therapy ${ }^{17,20}$ or specialty asthma care. ${ }^{21-23}$ In US research by Crocker et al. ${ }^{18}$ and Butz et al., ${ }^{24}$ SABA use was high among inner-city children, with hospitalisation for asthma five times more likely in high SABA users than in low-to-moderate users, ${ }^{24}$ whereas twice as many black children had asthma-related AED visits (39 vs $18 \%$ ) and hospitalisations (12 vs $5 \%$,) compared with white children. ${ }^{18}$

To examine the prevalence of sub-optimal prescribing and differences in asthma outcomes, this study linked primary and secondary care records from a large multi-ethnic inner-city population of patients aged 5-75 years with asthma, to address the following questions:

\footnotetext{
${ }^{1}$ Clinical Effectiveness Group, Centre for Primary Care and Public Health, Queen Mary University of London, London, UK; ${ }^{2}$ Asthma UK Centre for Applied Research, Queen Mary University of London, London, UK and ${ }^{3}$ Respiratory Critical Care and Anaesthesia Section, University College London, Institute of Child Health, London, UK. Correspondence: SA Hull (s.a.hull@qmul.ac.uk)

${ }^{4}$ These authors contributed equally to this work.

Received 16 March 2016; revised 8 June 2016; accepted 17 June 2016
} 
- How common is the excessive prescription of SABA inhalers for people with asthma?

- How common is the prescription of LABA inhalers without co-prescription of an ICS?

- Is excessive SABA prescribing and solo LABA prescribing associated with adverse morbidity, including hospitalisation?

- Which population groups are at an increased risk of hospitalisation with asthma?

\section{RESULTS}

Among our study population of 35,864 cases, $67 \%$ of the child and adolescent groups and $46 \%$ of the adult groups were of Black or South Asian ethnicity (Table 1). Smoking rates for adults with asthma (20\%) are similar to that for the whole East London population. ${ }^{25}$ Over $93 \%$ of patients had an asthma review recorded and $82 \%$ had an asthma management plan. BTS asthma treatment step was recorded for $86 \%$. The overall annual non-elective admission episode rate for asthma was 2.4/100 population. Crude admission episode rates were highest among the youngest group (Table 1).

Excess SABA prescribing

Among the total asthma population, $10.2 \%(3,671 / 35,864)$ were prescribed $>12$ SABA inhalers a year (Table 1). These high rates of SABA prescribing were observed among $5.9 \%$ of children and adolescents, and in $13.6 \%$ of adults.

Treatment by SABA alone

Table 2 shows asthma severity, primary care management and hospital admissions among the 8,227 cases $(22.8 \%)$ in whom SABA

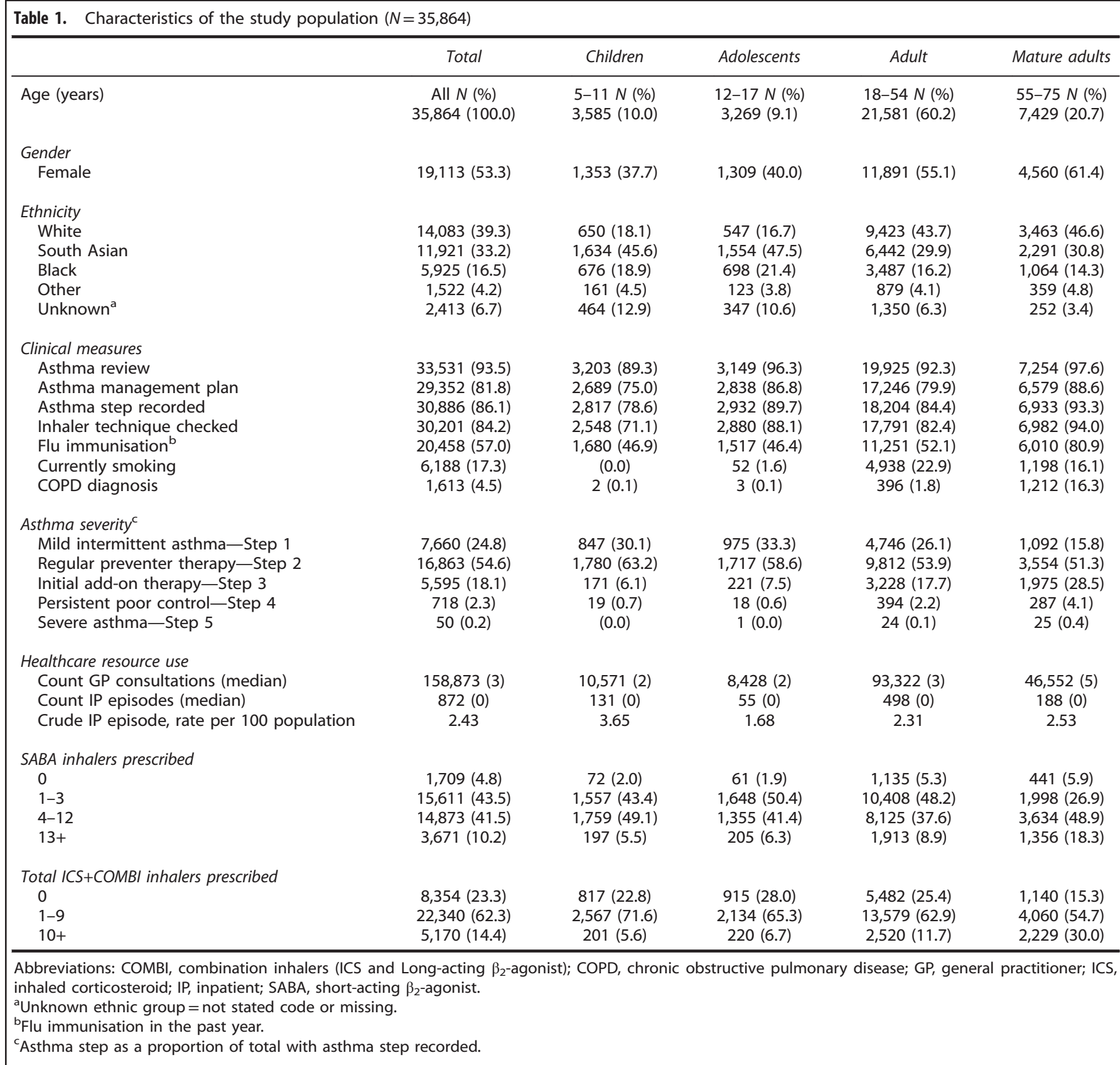


Table 2. Severity and clinical management of asthma population prescribed SABA alone, by number of SABA inhalers $(N=8,227)$

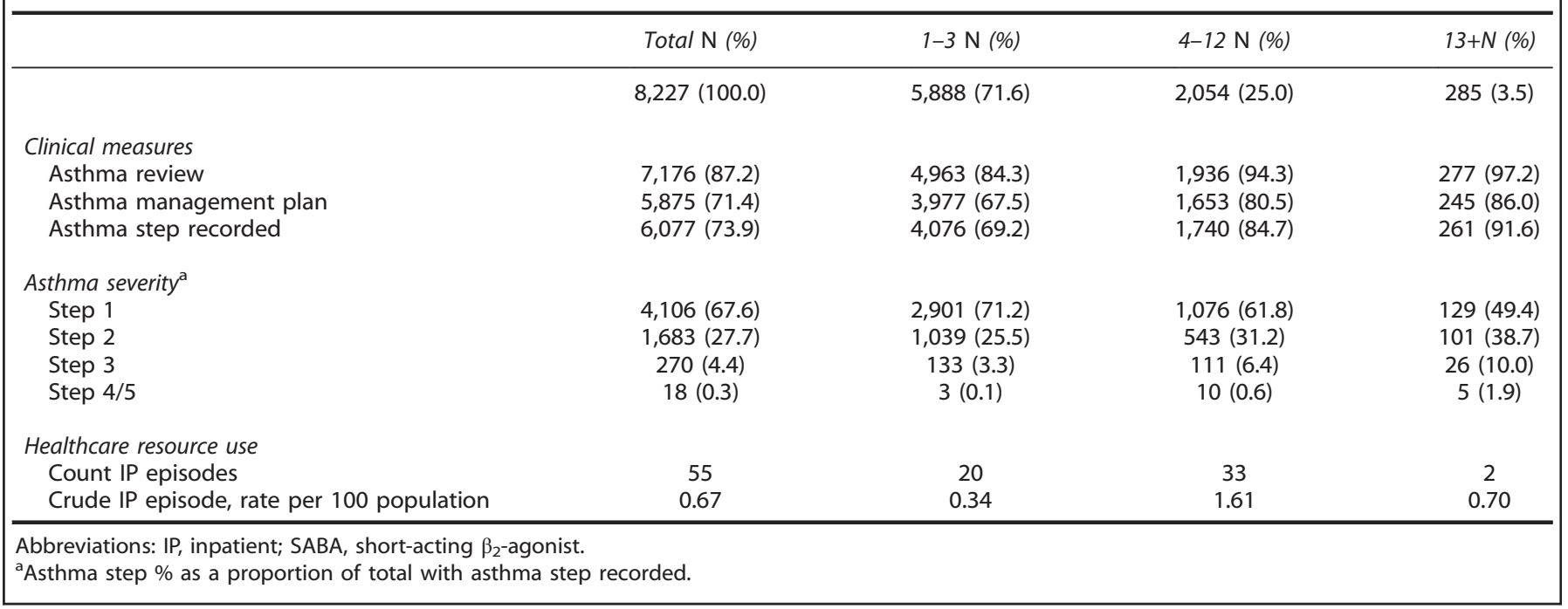

Table 3. Severity and clinical management of asthma population prescribed 1-9 ICS+COMBI per year, by number of SABA inhalers $(N=20,884)$

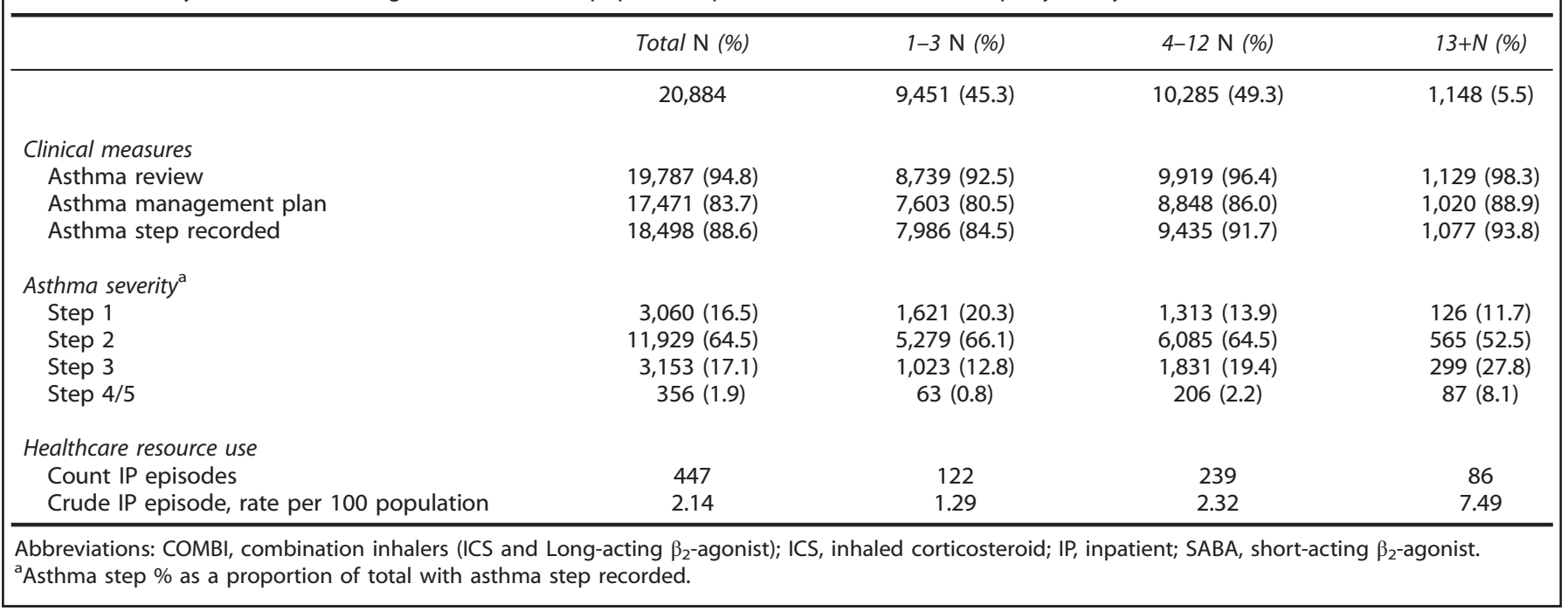

inhalers were prescribed as the sole treatment. BTS asthma treatment step 1 was recorded in $68 \%$ of cases, and in $87 \%$ of cases an asthma review was carried out in the previous year. Within this group, 3.5\% (285 cases) were prescribed $>12$ SABA inhalers a year. The crude asthma admission rate was $0.67 \%$.

Treatment by ICS or COMBI with SABA

The majority $(27,637,77 \%)$ of the population with asthma was prescribed ICS or COMBI treatment, as well as SABA inhalers. Among these, 20,884 (76\%) were prescribed fewer than 10 ICS canisters a year, which we considered a marker of sub-optimal preventer treatment. $^{4}$

Table 3 shows asthma severity, primary care management and hospital admissions among the 20,884 cases who were prescribed $<10$ ICS or combination inhalers-ICS and Long-acting $\beta_{2}$-agonist (COMBI) inhalers a year. Within this group, BTS asthma treatment step 2 was recorded in $65 \%$, and in $95 \%$ of cases an asthma review was carried out in the previous year; $5.5 \%$ of cases were prescribed $>12$ SABA canisters a year. The crude hospital admission episode rate for asthma rises from 1.3 to 7.5 per 100 population as the number of SABA inhalers prescribed rises from 1-3 to $13+$ a year.

The greatest number of emergency hospital admissions for asthma (447 admissions) occurs in this group of people prescribed $<10$ ICS inhalers a year. Among this group, we estimate a number needed to treat (NNT) of 16 to potentially reduce the $7.5 \%$ risk of admission in the high SABA use group to the $2 \%$ risk of admission seen in those using $\leqslant 12$ SABA inhalers.

Use of LABA without concomitant inhaled steroids

Among the asthma population (excluding all those with a read coded COPD diagnosis), $0.3 \%$ (105) of the cases had a LABA prescribed without ICS. Asthma reviews were completed for $88 \%$ of cases, and there were no admissions among this group (Supplementary Appendix 1).

Risk of emergency hospital admission

Multivariate analyses (Table 4) showed that in both children and adults the risk of admission rose steadily when SABA prescribing 
Table 4. Multivariate model for risk of admission for children (5-17 years) and for adults (18-75 years)

\begin{tabular}{|c|c|c|c|c|c|c|}
\hline & \multicolumn{3}{|c|}{ Children $(5-17) \mathrm{N}^{\mathrm{a}}=6,853$} & \multicolumn{3}{|c|}{ Adults $(18-75) \mathrm{N}^{\mathrm{a}}=28,992$} \\
\hline & $O R$ & $95 \% \mathrm{Cl}$ & $\mathrm{P}$ value & $O R$ & $95 \% \mathrm{Cl}$ & $\mathrm{P}$ value \\
\hline \multicolumn{7}{|l|}{ Gender } \\
\hline Male (ref) & 1 & & & 1 & & \\
\hline Female & 1.36 & $(0.98-1.89)$ & 0.07 & 1.34 & $(1.03-1.75)$ & 0.03 \\
\hline Age & 0.85 & $(0.81-0.90)$ & $<0.00$ & 0.98 & $(0.97-0.99)$ & 0.00 \\
\hline \multicolumn{7}{|l|}{ Ethnicity $^{\mathrm{b}}$} \\
\hline White (ref) & 1 & & & 1 & & \\
\hline $\begin{array}{l}\text { South } \\
\text { Asian }\end{array}$ & 1.47 & $(0.83-2.62)$ & 0.19 & 1.83 & $(1.36-2.47)$ & $<0.00$ \\
\hline Black & 1.21 & $(0.61-2.40)$ & 0.58 & 2.30 & $(1.64-3.23)$ & $<0.00$ \\
\hline \multicolumn{7}{|c|}{ Flu immunisation ${ }^{c}$} \\
\hline No (ref) & 1 & & & 1 & & \\
\hline Yes & 1.01 & $(0.75-1.38)$ & 0.93 & 1.03 & $(0.74-1.43)$ & 0.85 \\
\hline \multicolumn{7}{|c|}{ Currently smoking } \\
\hline No (ref) & NA & & & 1 & & \\
\hline Yes & NA & NA & NA & 0.83 & $(0.61-1.12)$ & 0.23 \\
\hline \multicolumn{7}{|l|}{ COPD diagnosis } \\
\hline No (ref) & NA & & & 1 & & \\
\hline Yes & NA & NA & NA & 0.99 & $(0.59-1.68)$ & 0.98 \\
\hline \multicolumn{7}{|c|}{ SABA inhalers prescribed } \\
\hline $1-3($ ref $)$ & 1 & & & 1 & & \\
\hline 0 & 1.03 & $(0.25-4.36)$ & 0.96 & 0.81 & $(0.37$ & 0.60 \\
\hline $4-12$ & 1.66 & $(1.13-2.43)$ & 0.01 & 1.71 & $(1.20-2.46)$ & $<0.00$ \\
\hline $13+$ & 4.09 & $(2.01-8.34)$ & $<0.00$ & 3.22 & $(2.04-5.07)$ & $<0.00$ \\
\hline \multicolumn{7}{|l|}{ Asthma severity } \\
\hline Step 1 (ref) & 1 & & & 1 & & \\
\hline Step 2 & 1.30 & $(0.76-2.24)$ & 0.33 & 1.24 & $(0.79-1.97)$ & 0.35 \\
\hline Step 3 & 2.73 & $(1.41-5.28)$ & $<0.00$ & 2.90 & $(1.79-4.69)$ & $<0.00$ \\
\hline Step $4 / 5$ & 5.54 & $(1.50-20.51)$ & 0.01 & 9.42 & $(5.27-16.84)$ & $<0.00$ \\
\hline \multicolumn{7}{|c|}{ GP consultation rate per patient } \\
\hline $0-1$ (ref) & 1 & & & 1 & & \\
\hline $2-6$ & 1.32 & $(0.92-1.90)$ & 0.13 & 1.59 & $(0.99-2.57)$ & 0.06 \\
\hline$>6$ & 2.58 & $(1.43-4.66)$ & $<0.00$ & 2.80 & $(1.70-4.63)$ & 0.00 \\
\hline \multicolumn{7}{|c|}{$\begin{array}{l}\text { Adjusted for IMD2010 quintile, total ICS+COMBI inhalers and practice } \\
\text { clustering. } \\
\text { Abbreviations: } \mathrm{Cl} \text {, confidence Interval; COMBI, combination inhalers } \\
\text { (ICS and long-acting } \beta_{2} \text {-agonist); COPD, chronic obstructive pulmonary } \\
\text { disease; ICS, inhaled corticosteroid; OR, odds ratio; NA, not applicable; } \\
\text { SABA, short-acting } \beta_{2} \text {-agonist. } \\
{ }^{\mathrm{a}} \mathrm{N}=\text { cases contributing to the model. } \\
\mathrm{b}_{1} \text { Other' and 'unknown' ethnicity categories not shown. } \\
{ }^{c} \text { Flu immunisation in the past year. }\end{array}$} \\
\hline
\end{tabular}

exceeded 1-3 inhalers a year, and when BTS asthma treatment step was $>2$. Children and women had a higher risk of admission. Among adults, but not children, the risk of admission was increased for those with Black or south Asian ethnicity in comparison with White groups. Further analysis by ethnicity did not suggest differences in primary care management or prescribing to account for these findings (Table 5).

Supplementary Appendix 2 details the characteristics of the 410 individuals who accounted for 872 episodes of asthma admission. These reflect the factors identified in the multivariate model, and the proportions of asthma reviews and management plans did not differ from the whole asthma population.
Table 5. Characteristics of major ethnic groups ${ }^{a}$ for all adults in the asthma population $(N=29,010)$, percentages shown

\begin{tabular}{|c|c|c|c|c|}
\hline & Total $\%$ & White \% & $\begin{array}{l}\text { South } \\
\text { Asian \% }\end{array}$ & Black \% \\
\hline Number & 29,010 & 12,886 & 8,733 & 4,551 \\
\hline \multicolumn{5}{|l|}{ Gender } \\
\hline Female & 56.7 & 56.9 & 53.2 & 63.4 \\
\hline \multicolumn{5}{|l|}{ Age bands } \\
\hline $18-54$ & 74.4 & 73.1 & 73.8 & 76.6 \\
\hline $55-75$ & 25.6 & 26.9 & 26.2 & 23.4 \\
\hline \multicolumn{5}{|l|}{ Clinical measures } \\
\hline Asthma review & 93.7 & 92.4 & 95.8 & 95.6 \\
\hline Asthma management plan & 82.1 & 78.9 & 88.5 & 84.6 \\
\hline Asthma step recorded & 86.6 & 84.7 & 90.5 & 89.0 \\
\hline Inhaler technique checked & 85.4 & 83.1 & 89.9 & 89.0 \\
\hline Flu immunisation ${ }^{\mathrm{b}}$ & 59.5 & 55.0 & 70.0 & 56.7 \\
\hline Currently smoking & 21.2 & 27.0 & 14.5 & 18.3 \\
\hline COPD diagnosis & 5.5 & 8.6 & 3.3 & 2.7 \\
\hline \multicolumn{5}{|l|}{ Asthma severity $^{c}$} \\
\hline Step 1 & 23.2 & 22.8 & 22.2 & 24.1 \\
\hline Step 2 & 53.2 & 50.1 & 56.2 & 56.7 \\
\hline Step 3 & 20.7 & 23.4 & 19.4 & 17.1 \\
\hline Step $4 / 5$ & 2.9 & 3.7 & 2.2 & 2.1 \\
\hline \multicolumn{5}{|l|}{ SABA inhalers prescribed } \\
\hline 0 & 5.4 & 5.5 & 5.7 & 4.6 \\
\hline $1-3$ & 42.8 & 42.1 & 40.4 & 45.0 \\
\hline $4-12$ & 40.5 & 40.0 & 42.2 & 41.4 \\
\hline $13+$ & 11.3 & 12.4 & 11.7 & 9.0 \\
\hline \multicolumn{5}{|c|}{ Total ICS+COMBI inhalers prescribed } \\
\hline 0 & 22.8 & 23.7 & 19.8 & 22.7 \\
\hline $1-9$ & 60.8 & 59.4 & 62.2 & 63.6 \\
\hline $10+$ & 16.4 & 16.9 & 18.0 & 13.7 \\
\hline \multicolumn{5}{|l|}{ Healthcare resource use } \\
\hline Count IP episodes & 686 & 271 & 246 & 116 \\
\hline $\begin{array}{l}\text { Crude IP episode, rate per } \\
100 \text { population }\end{array}$ & 2.36 & 2.10 & 2.82 & 2.55 \\
\hline \multicolumn{5}{|c|}{ 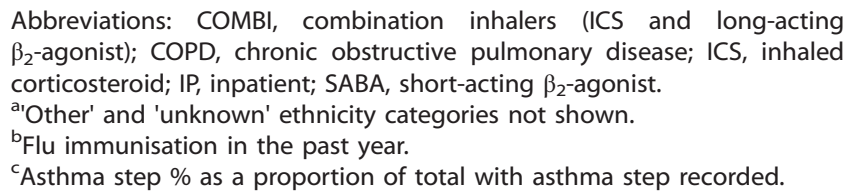 } \\
\hline
\end{tabular}

\section{DISCUSSION}

Main findings

We report the first UK population-based analysis of prescribing and risk of hospitalisation in a multi-ethnic population. Among the study population of 35,864 people with asthma, the results showed high levels of recorded asthma reviews (93\%) compared with the Quality and Outcomes Framework (QOF) data for England 2014-15, which report that $76 \%$ of patients on asthma registers received an asthma review in the previous 12 months. ${ }^{26}$ Our results also showed that $82 \%$ of the population received asthma management plans, suggesting a high level of guideline-based primary care within the East London asthma population.

It is chastening to observe that among adults with asthma the prevalence of smoking is the same as the general population. This suggests that although smoking status for those with asthma is well-recorded, smoking cessation interventions in primary care are either under-utilised or insufficient to support people with asthma to stop smoking. 
Prescribing for asthma

Of those prescribed SABA as the sole treatment, $3.5 \%$ of cases were prescribed $>12$ SABA in the previous year. In all, $95 \%$ of cases were documented as BTS asthma treatment step 1 or 2, suggesting that those treated with SABA alone had milder asthma and are at a lower risk for admission. However, it is likely that some cases in this group would benefit from additional ICS treatment.

The greatest burden of emergency hospital admission for asthma (447 admissions) occurred among the population requiring inhaled steroids but prescribed less than 10 ICS inhalers a year. In this group, rising numbers of prescribed SABA canisters is a clear marker of risk for hospital admission.

In a small number of cases $(0.3 \%)$, LABAs were prescribed without an ICS. LABAs have the potential to increase the risk of asthma mortality when used by patients with unstable asthma without concomitant ICS therapy or scheduled medical review; ${ }^{27}$ however, there is no evidence of an increased risk of asthma mortality with combination ICS/LABA inhaler therapy in asthma. ${ }^{28}$

Interpretation of findings in relation to previously published work Reports from North America suggest that increasing use of more than three SABA inhalers per year is associated with an increased risk of asthma-related hospitalisation. ${ }^{1,24,29-33}$ In the absence of similar studies in the UK, our results confirm that using more than three SABA inhalers per year is an independent risk factor for asthma-related hospitalisation in both children and adults.

Previous studies ${ }^{12,18,34}$ have found that children from ethnic minority groups have higher rates of admission than those in the White population, with the most recent UK data reported in $1998 .^{13}$ We did not observe this difference, suggesting that all children in East London get equal access to primary asthma care management. A recent report on ethnic variations in asthma hospital admission, re-admission and deaths in Scotland ${ }^{14}$ observed a modestly increased rate of hospital admission for asthma among the Pakistani and Indian populations, but not in those of African ethnicity. In contrast, we find that adults from Black or south Asian ethnicity have a twofold risk of admission in comparison with those of White background. We find no indication that these groups have more severe asthma, or have different patterns of primary care management or prescribing. This suggests that there may be differences in health-seeking behaviour or self-management related to culture, language or asthma understanding, which we are not able to capture in a database study.

\section{Strengths and limitations of this study'}

These results are based on asthma cases from a population of almost one million GP-registered patients in East London, linked to 'real-time' hospital activity data. The advantage of this contiguous practice population data set is that it avoids the selective bias of practice 'opt-in'. Results from this study will be generalisable to other inner urban populations in the UK. With over $93 \%$ ethnicity recording in this urban, multi-ethnic population, we are able to explore the contribution of ethnicity and deprivation alongside other established risk factors for asthma admission.

The prescribing data are based on electronic prescriptions issued by GPs; hence, this will include non-dispensed items (lost, unused, incorrect) in contrast to studies elsewhere, which have used dispensing data., ${ }^{14,29-32}$ In the absence of medication-dispensing data linked with medical records in the UK, patient-level primary care prescribing data can be used to assess medication usage $\mathrm{e}^{35}$ and is a useful predictor of dispensing-based adherence. ${ }^{36}$ In addition, we were not able to link oral steroid use for asthma exacerbations, or capture 'rescue steroid courses' initiated by patients.

Although we obtained Secondary Uses Services (SUS) data on asthma-related hospitalisations, we were unable to examine asthma attendances at AED because of the low rates of AED problem coding in the linked data set (see Materials and methods section).

Implications for future research, policy and practice

The electronic surveillance of prescription refill frequency in primary care has been recommended to alert clinicians to patients being prescribed excessive quantities of $\mathrm{SABAs}^{4}$ to allow for more frequent monitoring of those at risk of exacerbation. Computer decision support systems, which include electronic alerts, are increasingly used globally in the policy drive to improve prescribing safety. Those with asthma who are under-prescribed ICS and over-prescribed SABA account for the majority of hospital admissions. We recommend that electronic surveillance of prescribing be introduced in primary care practices to identify this at-risk population. Previous research shows that disproportionately few patients are responsible for a large component of total asthma direct medical costs; ${ }^{33}$ therefore, the identification of high-risk asthma populations might allow for targeted interventions to improve asthma control and reduce healthcare resource use.

Despite guideline recommendations that LABA should be prescribed in fixed-dose-combination ICS/LABA inhalers for the treatment of asthma, 5,6 our results show that clinicians do not always adhere to guidelines. We support previous recommendations ${ }^{37}$ suggesting practice strategies which detect and feedback to clinicians inappropriate LABA monotherapy. Furthermore, LABA/ICS therapy should only be available for prescription in a single device combination inhaler for the management of asthma.

\section{Conclusions}

In this study, we identified a twofold risk in hospital admissions for asthma in adults of ethnic minority backgrounds but not in children and adolescents of ethnic minority backgrounds. We found no variation in the prescribing and management of ethnic minority populations to account for these differences. A variety of possible explanations have been suggested for the observed ethnic inequalities in the burden of asthma, ${ }^{38}$ including lifestyle and environment, culture, communication issues and the nature of doctor-patient interactions. Further research addressing the social, cultural and psychological issues experienced by ethnic minorities is necessary to explain ethnic variations in asthma hospitalisations and to effect change in asthma outcomes.

\section{MATERIALS AND METHODS}

This study was set in the three geographically contiguous East London clinical commissioning groups (CCGs) of Newham, Tower Hamlets and City and Hackney, with a combined GP-registered population of 942,511 in 2015. In the 2011 UK census, $48 \%$ of the population in these three CCGs was recorded to be of non-White ethnic origin and among the eight most socially deprived localities in Britain. ${ }^{39}$

\section{Data sources}

In August 2015, anonymised demographic and clinical data were extracted from the North and East London Commissioning Support Unit (NELCSU), which holds EMIS-Web primary care data linked to hospital SUS data. ${ }^{40}$ Data were obtained for all patients aged 5-75 years: children (5-11 years), adolescents (12-17 years), adults (18-54 years) and mature adults (55-75 years) currently registered with $139 / 140$ general practices in the area. Data were extracted on secure N3 terminals using SQL Server Management Studio (2014), which interfaces with the CSU databases. All data were 
anonymous and managed according to UK NHS information governance requirements.

\section{Clinical and prescribing variables}

The study population was identified using the read code set for asthma used by the UK QOF. Among 942,511 registered patients, we identified 35,864 cases, aged 5-75 years, with a recorded diagnosis of asthma, and who were prescribed $\geqslant 1$ inhaled asthma medication in the previous 12 months. This formed our study population for analysis.

We extracted data on clinical variables, including smoking status, influenza immunisation and the presence of COPD, and aspects of asthma care, including the BTS asthma treatment steps, the presence of asthma review, inhaler technique and asthma management plans. For all asthma care variables, the most recent value in the previous year (August 2014-August 2015) was used. Prescribing data included all inhaled asthma medications issued in the previous year. Data were converted to annual numbers of inhalers issued in the following therapeutic categories, SABA, LABA, ICS and COMBI.

\section{Ethnicity and demographic data}

Self-reported ethnicity was recorded at the practice during registration or routine consultation. Ethnic categories are based on the UK 2011 census and for this study were condensed into three major categories: White (British, Irish, other White), Black (Black African, Black Caribbean, Black British, other Black and mixed Black) and South Asian (Bangladeshi, Pakistani, Indian, Sri Lankan, British Asian, other South Asian or mixed Asian). The index of multiple deprivation (IMD2010) score (derived from census variables and linked to patient place of residence) was used as a measure of social deprivation, categorised in quintiles of the study population. $^{41}$

Health Service use Primary care consultation data for the previous year were extracted as contacts with General Practitioners either in the surgery or at home, and telephone contacts. Non-elective inpatient hospital admissions where asthma was recorded as the primary cause were collected using International Classification of Diseases (ICD-10) codes for Asthma (J45) and Acute Severe Asthma (J46). ${ }^{42}$ Data were extracted for all AED visits for the study population in the previous year. However, the reason for AED attendance was missing in $>95 \%$ of instances; hence, these data were not used in the analysis.

\section{Statistical analysis}

Statistical analyses were performed using Stata version 12 (StataCorp LLP, College Station, TX, USA). On the basis of advice from community pharmacists and CCG-prescribing advisors, inhaler prescriptions were examined, and those patients with more than four inhalers of any one type prescribed on a single date were excluded from the analysis as likely to represent prescribing errors. This constituted 289/36,153 (0.8\%) of cases. To examine the contribution of factors to risk of admission with asthma, multivariate models were constructed using potential explanatory variables (Table 1). We examined collinearity, finding a significant association (Spearman's $\rho=0.6$ ) between the prescribing rates of SABA and ICS+COMBI. As potentially important clinical predictors of hospital admission, both were included in the final model.

\section{ACKNOWLEDGEMENTS}

We thank Asthma UK Centre for Applied Research for part-funding, the staff at the Clinical Effectiveness Group QMUL for data extraction and the participating GPs for their co-operation, without whom such studies would be impossible. Ethical approval was not required, as aggregated, anonymised patient-level data are reported in this study. All GPs in the participating East London practices consented to the use of their anonymised patient data for research for patient benefit.

\section{CONTRIBUTIONS}

S.A.H., S.M. and C.G. contributed to the plan and/or design of the study. S.A.H. and K.H. contributed to data analysis. S.A.H., S.M., S.J.C.T., K.P. and C.G. contributed to data interpretation. S.A.H. and S.M. were involved in drafting of the manuscript. K.H., S.J.C. T., K.P. and C.G. commented on draft versions. All authors read and approved the final manuscript.

\section{COMPETING INTERESTS}

CG is an Assistant Editor of npj Primary Care Respiratory Medicine, but was not involved in the editorial review of, nor the decision to publish this article. The other authors declare no conflict of interest.

\section{FUNDING}

This work was partly supported by funding from the Asthma UK Centre for Applied Research.

\section{REFERENCES}

1. Paris, J. et al. Relationship between recent short-acting beta-agonist use and subsequent asthma exacerbations. Ann. Allergy Asthma Immunol. 101, 482-487 (2008).

2. Butz, M. et al. Seasonal patterns of controller and rescue medication dispensed in underserved children with asthma. J. Asthma 45, 800 (2008).

3. Patel, M. et al. Metrics of salbutamol use as predictors of future adverse outcomes in asthma. Clin. Exp. Allergy 43, 1144-1151 (2013).

4. Royal College of Physicians. Why Asthma Still Kills-The National Review of Asthma Deaths (NRAD) Confidential Enquiry report 2014. Available at https://www.rcplondon.ac.uk/projects/national-review-asthma-deaths. Accessed on 30 November 2015.

5. Global Initiative for Asthma. Global Strategy for Asthma Management and Prevention 2016. Available at www.ginasthma.org. Accessed on 10 May 2016.

6. British Thoracic Society/Scottish Intercollegiate Guidelines Network. British guideline on the management of asthma. Thorax 69 (Suppl 1), 1-192 (2014).

7. Netuveli, G. et al. Ethnic variations in UK asthma frequency, morbidity, and health-service use: a systematic review and meta-analysis. Lancet (London, England) 365, 312 (2005).

8. Duran-Tauleria, E., Rona, R. J., Chinn, S. \& Burney, P. Influence of ethnic group on asthma treatment in children in 1990-1: national cross sectional study. BMJ. 313, 148-152 (1996).

9. Bryant-Stephens, T. Asthma disparities in urban environments. J. Allergy Clin. Immunol. 123, 1199-1206, quiz 207-8 (2009).

10. Brotanek, J. M., Halterman, J., Auinger, P. \& Weitzman, M. Inadequate access to care among children with asthma from Spanish-speaking families. J. Health Care Poor Underserved. 16, 63-73 (2005).

11. Griffiths, C. et al. Influences on hospital admission for asthma in south Asian and white adults: qualitative interview study. BMJ. 323, 962 (2001).

12. Boudreaux, E. D., Emond, S. D., Clark, S. \& Camargo, C. A. Jr. Race/ethnicity and asthma among children presenting to the emergency department: differences in disease severity and management. Pediatrics 111, e615-e621 (2003).

13. Gilthorpe, M. S. et al. Variations in hospitalization rates for asthma among black and minority ethnic communities. Respir. Med. 92, 642-648 (1998).

14. Sheikh, A. et al. Ethnic variations in asthma hospital admission, readmission and death: a retrospective, national cohort study of 4.62 million people in Scotland. BMC Med. 14, 1-9 (2016).

15. The Tower Hamlets Joint Strategic Needs Assessment Reference Group. Adult Asthma Factsheet 2015. Available at http://www.towerhamlets.gov.uk/Docu ments/Public-Health/TH-JSNA-Factsheet-Asthma-2015.pdf. Accessed on 01 February 2016.

16. Apter, A. J. et al. Modifiable barriers to adherence to inhaled steroids among adults with asthma: it's not just black and white. J. Allergy Clin. Immunol. 111, 1219-1226 (2003).

17. Diaz, T. et al. Medication use among children with asthma in East Harlem. Pediatrics 105, 1188-1193 (2000).

18. Crocker, D. et al. Racial and ethnic disparities in asthma medication usage and health-care utilization: data from the National Asthma Survey. Chest 136, 1063-1071 (2009).

19. Bollinger, M. E. et al. Prescription fill patterns in underserved children with asthma receiving subspecialty care. Ann. Allergy Asthma Immunol. 111, 185-189 (2013).

20. Ortega, N. et al. Impact of site of care, race, and Hispanic ethnicity on medication use for childhood asthma. Pediatrics 109, E1 (2002).

21. Flores, G. et al. Urban minority children with asthma: substantial morbidity, compromised quality and access to specialists, and the importance of poverty and specialty care. J. Asthma 46, 392-398 (2009).

22. Stewart, K. A. et al. Differences in prevalence, treatment, and outcomes of asthma among a diverse population of children with equal access to care: findings from a study in the military health system. Arch Pediatr. Adolesc. Med. 164, 720-726 (2010).

23. Butz, A. M. et al. Factors associated with second-hand smoke exposure in young inner-city children with asthma. J. Asthma 48, 449-457 (2011). 
24. Butz, A. M. et al. Factors associated with high short-acting beta2-agonist use in urban children with asthma. Ann. Allergy Asthma Immunol. 114, 385-392 (2015).

25. Public Health England. Local Tobacco Control Profiles 2014. Available at http://www. tobaccoprofiles.info/profile/tobacco-control/data. Accessed on 10 January 2016.

26. Health and Social Care Information Centre. Recorded disease prevalence, achievements and exceptions. Quality and Outcomes Framework (QOF) for April 2014-March 2015, England. Asthma. Available at http://www.hscic.gov.uk/catalo gue/PUB18887. Accessed on 10 December 2015.

27. Nelson, H. S., Weiss, S. T., Bleecker, E. R., Yancey, S. W. \& Dorinsky, P. M. The Salmeterol Multicenter Asthma Research Trial: a comparison of usual pharmacotherapy for asthma or usual pharmacotherapy plus salmeterol. Chest 129, 15-26 (2006).

28. Weatherall, M., Wijesinghe, M., Perrin, K., Harwood, M. \& Beasley, R. Meta-analysis of the risk of mortality with salmeterol and the effect of concomitant inhaled corticosteroid therapy. Thorax 65, 39-43 (2010).

29. Stanford, R. H., Shah, M. B., D'Souza, A. O., Dhamane, A. D. \& Schatz, M. Short-acting beta-agonist use and its ability to predict future asthma-related outcomes. Ann. Allergy Asthma Immunol. 109, 403-407 (2012).

30. Silver, H. S. et al. Quarterly assessment of short-acting beta(2)-adrenergic agonist use as a predictor of subsequent health care use for asthmatic patients in the United States. J. Asthma 47, 660-666 (2010).

31. Anis, A. H. et al. Double trouble: impact of inappropriate use of asthma medication on the use of health care resources. CMAJ 164, 625-631 (2001).

32. Schatz, M. et al. Relationship of asthma control to asthma exacerbations using surrogate markers within a managed care database. Am. J. Manag. Care 16, 327-333 (2010)

33. Stephenson, J. J., Quimbo, R. A. \& Gutierrez, B. Subacute lack of asthma control as a predictor of subsequent acute asthma exacerbation in a managed care population. Am. J. Manag. Care 16, 108-114 (2010).

34. Miller, J. E. The effects of race/ethnicity and income on early childhood asthma prevalence and health care use. Am. J. Public Health. 90, 428-430 (2000).

35. Taylor, A., Chen, L.-C. \& Smith, M. D. Adherence to inhaled corticosteroids by asthmatic patients: measurement and modelling. Int. J. Clin. Pharmacy $\mathbf{3 6}$ 112-119 (2014)
36. Mabotuwana, T., Warren, J., Harrison, J. \& Kenealy, T. What can primary care prescribing data tell us about individual adherence to long-term medication?comparison to pharmacy dispensing data. Pharmacoepidemiol. Drug Saf. 18 956-964 (2009).

37. Morales, D. R. LABA monotherapy in asthma: an avoidable problem. Br. J. Gen. Pract. 63, 627-628 (2013).

38. Davidson, E., Liu, J. J. \& Sheikh, A. The impact of ethnicity on asthma care. Primary Care Respir. J. 19, 202-208 (2010).

39. Office for National Statistics. 2011 Census: KS201EW Ethnic group, local authorities in England and Wales. Available at http://www.ons.gov.uk/ons/pub lications/re-reference-tables.html?edition $=\mathrm{tcm} \% 3 \mathrm{~A} 77-286262$. Accessed on 02 December 2015.

40. Health and Social Care Information Centre. Secondary Uses Service (SUS). Available at www.hscic-gov.uk/sus2015. Accessed on 10 January 2016

41. Department for Communities and Local Government. English indices of deprivation 2015. Available at https://www.gov.uk/government/statistics/english-indicesof-deprivation-2015. Accessed on 10 January 2016.

42. World Health Organisation. International Statistical Classification of Diseases and Related Health Problems 10th Revision 2016. Available at http:// apps.who.int/classifications/icd10/browse/2016/en. Accessed on 12 January 2016

(c) (i)

This work is licensed under a Creative Commons Attribution 4.0 nternational License. The images or other third party material in this article are included in the article's Creative Commons license, unless indicated otherwise in the credit line; if the material is not included under the Creative Commons license, users will need to obtain permission from the license holder to reproduce the material. To view a copy of this license, visit http://creativecommons.org/licenses/ by/4.0/

(c) The Author(s) 2016

Supplementary Information accompanies the paper on the npj Primary Care Respiratory Medicine website (http://www.nature.com/npjpcrm) 